\title{
ORGANIZATION OF THE COMMITTEE ON ANTHROPOLOGY OF THE NATIONAL RESEARCH COUNCIL AND ITS ACTIVITIES FOR THE YEAR 1917
}

\author{
Bx W. H. HOLMES
}

At a meeting of the Executive Committee of the National Research Council held in Washington, January 6, 1917, the writer was appointed Chairman of the Committee on Anthropology of the Council, and the appointment was later confirmed by the President of the United States. Dr. Aleš Hrdlička was named as Secretary and the activities of the Committee were initiated by a careful study of the several fields with which it might be called upon to deal, and of the possibilities of accomplishing results of value to the nation.

The further organization of the Committee presented certain difficulties which were gradually overcome. It was important that its activities should not encroach upon the field of any other branch of science, and it soon became apparent that it would have to deal exclusively with the problems of the physical man. Due to these and other exigencies, it was not until August, 1917, that the Committee was fully organized.

The membership then was as follows:

William H. Holmes, Chairman, Head Curator, Department of Anthropology, U. S. National Museum.

Dr. Aleš Hrdlička, Secretary, Curator, Division of Physical Anthropology, U. S. National Museum.

Dr. Charles B. Davenport, Director, Station for Experimental Evolution, Cold Spring Harbor, N. J.

Mr. Madison Grant, Trustee, American Museum of Natural History, New York City.

Dr. Frederick L. Hoffman, Chief Statistician, The Prudential Insurance Company, Newark, N. J.

Dr. E. A. Hooton, Instructor in Anthropology, Harvard University, Cambridge, Mass.

Dr. George M. Kober, Dean of Medical Department, Georgetown University, Washington, D. C.

Dr. Tom A. Williams, Psychiatrist and Anthropologist, Washington, D. C.

In the spring Dr. Williams left for service in France and later in 
the year Dr. George Grant MacCurdy, of Yale University, was selected to fill the place.

Before the Committee as a whole could be called together, a series of recommendations were formulated, and submitted by the Chairman to the Research Council. They were as follows:

1. To regulate the measuring of recruits and the recording and utilization of the data obtained.

2. To revise the physical requirements in recruiting the new army as demanded by a consideration of the diversified characteristics of the many nationalities and races involved.

3. To utilize the opportunities offered by the recruiting of a great army for the prosecution of certain highly desirable researches in Physical Anthropology, especially those having a direct bearing on the future welfare of the race; and to gather statistics which should be available for comparative purposes in the near and far future.

A brief résumé of these recommendations was eventually published, under the title "Suggestions Relating to the New National Army by the Anthropological Committee of the National Research Council," in the Proceedings of the National Academy of Sciences, Vol. III, pp. 526-528, August, 1917. The object of the present communication is to discuss these recommendations more fully and to include also certain additional suggestions. made during the latter part of 1917, after the above mentioned report was submitted.

As early as February 16, 1917, certain proposals were formulated by the Secretary of the Committee which under the heading "A National Anthropometric Survey," were submitted to Dr. Charles D. Walcott, Secretary of the Smithsonian Institution, for presentation to the Council. These recommendations, which were necessarily of a tentative nature, called attention to the great opportunities for comprehensive anthropological investigations that must necessarily be presented in case of war and urged that these opportunities be utilized to secure anthropometric measurements sufficient to establish normal physical standards throughout the country. It was suggested that the researches in question should extend to from four to six of the most important environmental areas of the United States, namely, New England, the Appalachian region, the southernmost and the northernmost Central States, the semiarid southwest, and the humid northwestern sections, and that the observations should be directed to differences in development, physical strength, and anthropological type of the male population in these different regions. The results 
if accomplished would serve as standards for future anthropometric surveys of similar nature taken from generation to generation in the same regions, and form a basis for legislative and eugenic measures designed to correct or improve the physical status of the people wherever requisite. In addition it was recommended that when possible the investigations should be extended to the children of the several areas; and that similar physical standards be determined respecting the different classes of immigrants reaching this country, to be used in regulating the admission of foreign elements. The proposed researches would best be undertaken ty a National Anthropometric Survey Bureau under the auspices of the Smithsonian Institution, and in coöperation with the War Department, the Public Health Service, the Bureau of Immigration, and other like governmental auspices, together with well established outside institutions or agencies.

When war between the United States and the central European powers became inevitable and the first draft of recruits was called, the Anthropology Committee felt justified in offering several new suggestions. These were presented on April 18, 1917, to Dr. V.C.Vaughan of the Medical Branch of the National Council of Defense and a short time afterwards were formally submitted to the National Research Council. In May they were submitted again in an amended form, and on June 2 an opportunity was given to the Secretary to present. them orally before the Committee of the Medical Branch of the $\mathrm{Na}$ tional Defense Council, where they were received with much favor. On June 6 these suggestions were made to the Research Council in a still more detailed form. They read as follows:

\section{REGULATIONS OF METHODS AND INSTRUMENTS IN MEASURING RECRUITS}

The recruiting of a large army from all parts of the national population will present certain conditions in which Physical Anthropology may be of practical service, and afford many opportunities by means of which this and related branches of science may greatly benefit. These opportunities were well appreciated by the leaders of the Army Medical Service during the Civil War, which resulted in the several volumes of valuable even though imperfect data by Gould and Baxter with their associates, and in the collections which now constitute the bulk of the precious material preserved in the Army Medical Museum.

The examination of recruits for admission into the new Army will include certain observations and measurements which if properly regulated, and taken by simple, accurate, standardized instruments, 
would prove of much scientific value. The methods followed to-day, and also the instruments by which the measurements are taken, lack in uniformity as well as in accuracy. Unless a few necessary improvements are made in both, the data relating to a million or more men cannot be utilized by science with any confidence; and as properly revised regulations would not increase, but actually diminish the burdens of the examiners, the Committee takes the liberty of offering such a revision of the regulations and urging its adoption. An outline of the proposed modifications of the present examination blanks, and specifications for simple outfits of instruments, together with directions for the examiners, giving in plain language the instructions to be followed in taking measurements and physical observations, are herewith submitted.

In this as well as in other recommendations which the Committee has made, the utmost care has been taken not to add to, but rather to reduce the burdens of the medical examiners and the medical service of the Army. No additional tasks at this time unless of the highest practical importance could be justifiable or would be feasible.

The Committee advised that everything relating to measurements and other physical observations be segregated on one part of the regular enlistment blank; and that the blanks for the Army include observations on complexion, hair, and eye color, such as have always been carried by the blanks for the Navy. The following form is proposed, to constitute a part of the enlistment blank:

\section{PHYSICAI MEASUREMENTS AND OBSERVATIONS}

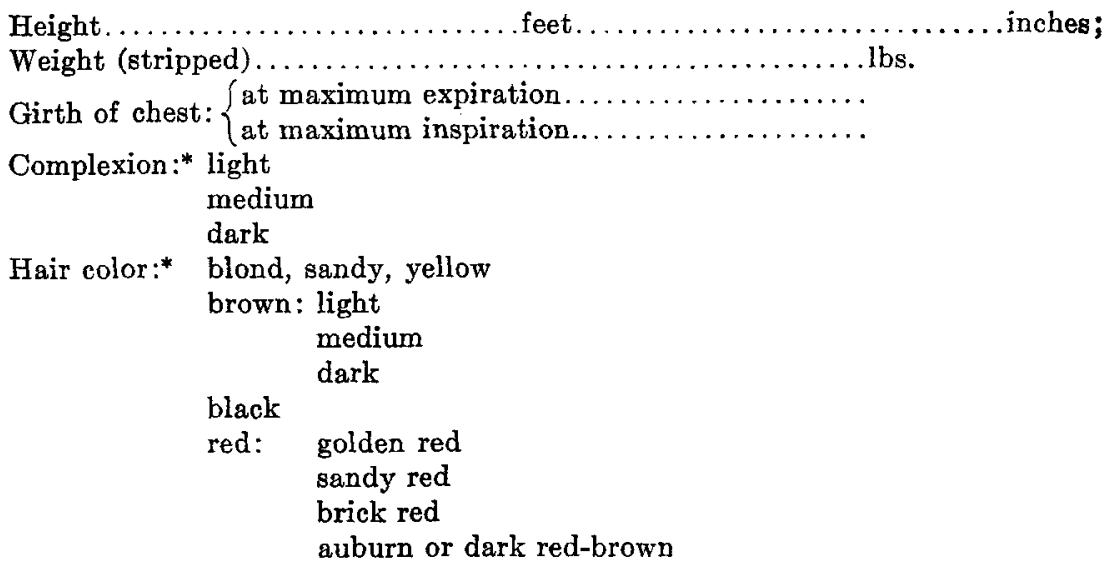


$\begin{array}{cc}\text { Eye color:* blue: light } & \begin{array}{l}\text { medium } \\ \text { deep }\end{array} \\ & \text { brown: light } \\ \text { medium } & \\ \text { deep } & \\ & \text { greenish } \\ \text { grey } & \\ \text { mixed or indeterminate }\end{array}$

*Underscore the term covering most closely your observations.

The directions relating to measurements of the recruits contained in the regular Army and Navy blanks are to be superseded by the following:

Directions for Measurements at the Recruiting Stations.-The measurements of recruits, aside from their military use, may, if accurate enough, be also utilized for scientific purposes, and it is therefore important that the directions given below be followed to the letter.

Instruments (to be provided by the Department)

A. Special linen or paper tape, 4 feet long, $1 \frac{3}{4}$ inches wide, for measuring height, with feet marked $4,5,6,7$.

B. Linen tape 4 feet long, $\frac{5}{8}$ inches wide, for measuring chest.

C. A wooden square, an adjunct to $A$.

\section{Procedure}

1. Select the best lighted part of the available wall space in the room where the men are being examined. If a choice is possible, select the side on which the light strikes the subject from the left side.

2. Measure with tape $A$ exactly three feet from the floor, and make a horizontal line at that point.

3. Fasten tape $A$ with suitable tacks or nails vertically on the wall, in such a way that its lower edge coincides with the three foot mark. The top of the tape will now be 7 feet from the ground.

4. Height: Place subject, undressed, against the tape on the wall. See to it that he stands straight, but without straining or stretching, touching the wall with his heels, buttocks, and shoulders, and holding his head so that he looks straight forward. The head may touch the tape on the wall but does not need to do so.

Apply wooden square horizontally to tape on the wall and bring it down on the head of the subject, with sufficient pressure to feel the hard calvarium, and carefully note the measurement, to the nearest $\frac{1}{8}$ of an inch.

5. Circumference of Chest: The subject should face the light as well as the examiner, and raise his elbows to about 45 degrees from the body.

Facing the recruit the examiner passes the narrow tape $(B)$ horizontally about the body, at the level of the nipples, and records measurements in deepest inspiration and utmost expiration. 
Sources of error to be strictly avoided: Conversation during measuring; interruptions; incorrect reading of scale; incorrect recording. Measurements or recording must not be relegated to an untrained assistant.

\section{Estimates on Instruments*}

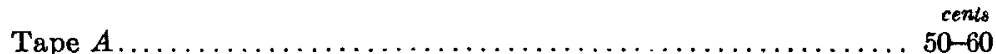

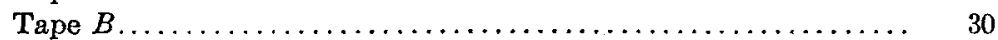

Wooden square................................... 20

* Actual estimates for large lots.

\section{MODIFICATION OF PHYSICAL REQUIREMENTS}

As good health with physical fitness are the foremost requirements of the soldier and the sailor, the men drafted by the United States for its new Army and Navy must be subjected to careful examination in these respects. The object of such examination must be the selection, not of the tallest and strongest men, but of all those who on the basis of our physical and physiological knowledge may reasonably be expected to be fit or competent for the tasks before them, or who may be made so during the period of training.

It is self-evident that any reduction in the physical standards for recruits below certain minima would be highly undesirable, as it might be attended with costly consequences; but it is also true that to make these minima unnecessarily high would exclude from the ranks many men well fitted to serve.

Certain standards relating to the physical development and to the health of recruits have long been established in this country and are now employed in the recruiting offices. These standards differ somewhat in the different branches of the service. They are probably sufficient in normal times, but they take no account of racial differences in stature, weight, etc., and give little consideration to the question of improvement in the individual that is bound to follow the six or nine months of training, medical supervision and outdoor life.

Under these conditions it would seem advisable that the subject of physical and hygienic requirements for the recruit be now subjected to careful medical and anthropological scrutiny.

Dentition: Under present regulations the recruit is expected to have twenty sound teeth, including four opposite incisors and four opposite molars. As the prevalent defective condition of the teeth in many cases is connected with the food and other habits of modern civilization, or with accidental conditions, rather than with disease, and as 
in a large majority of cases the condition of the teeth can readily be corrected by Army or Navy dentists, it would seem best that this stipulation be replaced by one permitting of more latitude in this direction. Possibly the following would meet the requirements: The recruit is expected to have twenty sound teeth, including four opposite incisors and four opposite molars; but if his physical condition is otherwise satisfactory, he may be accepted even though below this dental standard, provided the defects of the teeth are such as can be readily corrected by Army or Navy dentists.

Abnormalities: In the "Enlistment Instructions of the United States Navy, 1917," sec. 2, p. 35, in enumerating the various abnormalities which disqualify a recruit for acceptance the following are included:

Parasites of the skin or its appendages;

Deformity of the skull; $;^{1}$

Inequality of upper or lower extremities;

Color-blindness;

Polypi;

Great enlargement of tonsils;

A "predisposition" to heart or lung disease;

Enlarged abdominal organs;

Ingrowing nails;

Bad corns;

Large bunions;

Deformity of toes.

As many of these conditions, unless in aggravated form, can be readily cured or corrected and would interfere but little, if any, with the military efficiency of the subject, while strict adherence to these rules would exclude many individuals otherwise fit, it would seem that the regulations above referred to should be modified. This could be accomplished most simply by omitting the cases above mentioned, for they are practically included in the first clause of the paragraph, which stipulates that among the causes of disqualification are "any disease or deformity, either congenital or acquired, that would impair efficiency."

Stature Requirements: The present minimum requirement of stature, in any branch of the Army or the Navy, is 5 feet 4 inches. In the case of mountain artillery it is 5 feet 8 inches.

The minimum for the English infantry and some other branches of

1 Harmless scaphocephaly of the more moderate degrees is very common in the American negro. 
the service prior to the present war was 5 feet 2 inches, and it has since been reduced. On the Continent the minimum differs with the nationalities, but is as a rule lower than that of the United States. In many of these nationalities the average height of the adult male does not reach, barely equals, or only slightly surpasses the minimum requirement for the soldier of the United States. ${ }^{2}$ Many of these nationalities are well represented in this country. They include the Italians, Greeks, French, Mexicans, Spanish, Swiss, the Russian and Austrian Jews, many of the Slavs, the Magyars, Roumanians, Lithuanians, and even Germans. Should the present minimum in stature for the United States Army and Navy be rigidly adhered to, from onefourth to one-half of the men belonging to or descending from the nationalities mentioned would be excluded by this rule alone, thus resulting in serious disadvantages, the chief among which would be that of placing a disproportionate burden in the formation of the Army on the naturally taller native American.

In view of the above facts, and as small stature in a large majority of cases signifies normal fluctuation and not any weakness or degeneration, as has been repeatedly proven by the "bantam" regiments of England and other short stature troops of European countries, the Committee recommends that the minimum stature requirement for the new United States Army be reduced, for all branches of the service, to 60 or at most 62 inches; and that corresponding with this, the minimum weight requirement be reduced from 128 to 120 pounds.

The maximum weight, the circumference of the chest (minimum acceptable, 32 inches) and the chest expansion (minimum, 2 inches) of the present requirements need no modification.

III. ADVANCED ANTHROPOMETRIC WORK AT THE CONCENTRATION CAMPS - It was evident to the Committee that the measurements on the drafted men taken by the examining physicians all over the country, even if properly regulated in accordance with the recommendations of the Committee, could not give us information on many important

2 Approximate average height of the various nationalities:

\begin{tabular}{|c|c|c|}
\hline Itali & $\begin{array}{r}\text { Inches } \\
64.7\end{array}$ & Russian Jews..... \\
\hline Greek & 64.9 & Austrian Jews.. \\
\hline rench & 65.2 & Roumanians... \\
\hline wiss. . & 64.4 & Lithuanians. \\
\hline ustrial & 64.8 & Germans (in general). \\
\hline
\end{tabular}

Magyars................6.7 63.7 
points concerning the physical development and type of the population. If the great opportunity presented by the formation of the new Army was not to be lost to Anthropology, it was necessary to formulate plans for additional measurements and observations at some if not all of the camps, by specially trained examiners. Such work would practically represent what the Committee had in mind when it made its original suggestions relating to the National Anthropometric Survey. The formal recommendations by the Committee on this subject were as follows:

The sixteen or more concentration camps will afford a unique opportunity for anthropometric observations, one object of which would be to obtain data regarding the normal physical conditions of the American people of different descent, admixture, education, social class, occupation, and environment.

To utilize these opportunities the minimum requirement would be the selection of six of the camps representing the northeast, southeast, the northern middle States, the south, the southwest, and the northwest; and placing in each a specially trained young medical officer who would devote his time to the anthropometric work.

The investigations, reduced to the minimum, would consist of the measurement of stature and height sitting; of the three principal dimensions of the head; of two diameters of the face; of two diameters of the chest; and of more precise observations on the color of the skin, eyes, and hair than are practicable at the recruiting stations.

The training and equipment of the six medical officers would be undertaken by the Department of Anthropology of the United States National Museum. The data procured would be elaborated without cost by the Statistical Staff of the Prudential Insurance Company of America. Publication of the results would be facilitated as far as possible by the Smithsonian Institution.

The total period of the investigations could be limited to six months if found advisable. The officers required for conducting the observations should be appointed by the medical departments of the Army and the Navy. Their special training at the United States National Museum would require approximately one month.

The above suggestions were favorably received, but it was soon found that it would be quite difficult if not impossible to secure from the Government the medical officers needed for making the examinations. In looking for a way out of this difficulty the Committee met with the suggestion that the needed help could possibly be secured 
from the larger insurance companies of the country. It can be safely anticipated that Anthropology will before long play an important part in the examinations for life insurance, and the examinations in the camps would have given excellent training to young medical men in the employ of the various companies. It was therefore proposed to the insurance companies that each place at the disposal of the Committee, for a period of seven months, and at the expense of the company, one of its medical employees, who for the expenditure by the company would bring back the training and experience in anthropometry acquired under the auspices of the Committee. A number of promising answers were received to this proposition; but unfortunately considerable time elapsed before the subject could receive due consideration of the higher authorities, and meanwhile the medical staffs of the insurance companies were so depleted by the direct calls of the Army and Navy that eventually no men remained who could be spared for the anthropometric examinations.

Then there seemed to remain only one possibility before the Committee, which was to secure and train a half dozen young medical graduates of its own selection and have them do the work at the camps. Such men, however, would be, strictly speaking, employees of the Committee and as such would have to receive due compensation, which, with the expenses of the training period at Washington and that for the purchase of necessary instruments, was calculated collectively at $\$ 7,000$. This sum the Committee hoped to raise with the help of the Council. It was a modest sum considering the extent and importance of the work, and the prospects of results under such an arrangement were brighter than they would have been under either of the two previous propositions.

The blank proposed for this special examination, by the Secretary of the Committee, was as follows, the understanding being that the methods of securing the various measurements would follow strictly the International Anthropometric Agreements:

\section{SPECIAL EXAMINATIONS}

Name

Age.

Occupation

Born in (what State or country).

Birthplace (State or country):

of father....................., of mother.

of father's father.................., of mother's father.

of father's mother..............., of mother's mother 
MEASUREMENTS

\begin{tabular}{|c|c|}
\hline \multirow{5}{*}{ 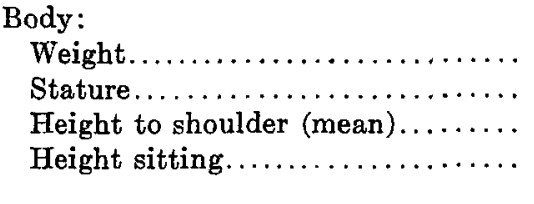 } & Face: \\
\hline & Length to nasion. \\
\hline & Length to crinion. . \\
\hline & Breadth, bizygom. \\
\hline & Misce \\
\hline Tead: & Shoul \\
\hline Deformatio & Bre: \\
\hline Lengt & Chest: \\
\hline Breadth. & Mean b \\
\hline & ipple heigh \\
\hline
\end{tabular}

OBSERVATIONS

Color of eyes...................

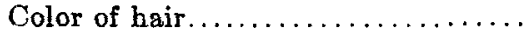

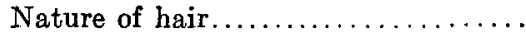

Nose. . .

Nasal septum.
Lips

Chin

Body and limbs

Dynamometric pressure

r. hand

1. hand.

\section{MATERIAL FOR FUTURE SCIENTIFIC RESEARCH}

Together with the preceding suggestions the Committee pointed out the opportunities and need of gathering scientific data and especially valuable specimens at the base hospitals. These suggestions were worded as follows:

The organization of the new Army will afford important opportunities for additional scientific research and the collection of data and specimens which should be utilized as far as practicable. Efforts in this direction were made in the Northern Army of the United States during the Civil War; the results are embodied in three volumes of data by Baxter and Gould, and in the collections of the Army Medical Museum. According to available information, more or less extended scientific researches are being conducted and illustrative collections made at the present time in connection with nearly all the armies of Europe.

The United States Army will include not only men of many nationalities, but also those of different races, such as the Indian, Negro, Filipino, and possibly Japanese and Chinese. Even under the best hygienic conditions and without actual participation in war a certain proportion of these must be expected to become ill and die in hospitals. The 
bodies of such dead cannot, as in peace, be transported hundreds or thousands of miles, perhaps, to their friends, but must be cremated or buried in the vicinity of the hospitals. These bodies offer a valuable opportunity for postmortem determinations, such as the cause of death as found at autopsy, the weight of the different internal organs, etc., and also for assembling specimens which would be of the utmost value to future pathological, anatomical and anthropological investigation. The Army Medical Museum and the United States National Museum would gladly take charge of the preparation and distribution of such material.

For the above purposes it is requisite that in each of the more important hospitals one member of the medical staff, preferably a pathologist or an assistant pathologist, be designated to gather needed records and specimens; and it is earnestly recommended that such a detail be made immediately on the establishment of each large army or navy hospital.

Shortly after submitting the above, the Secretary of the Committee made the additional recommendation to the Council that a specially well qualified anatomist or physical anthropologist be officially attached, if possible, to the Medical Service of the War Department and be commissioned to France for the purpose of making scientific observations and collecting suitable material in the hospitals in France.

\section{ADDITIONAL SUGGESTIONS}

During the latter part of 1917 the Chairman of the Committee transmitted to the Research Council some additional suggestions, to the following effect:

V. THE NEED OF PRESERVATION OF ANCIENT HUMAN REMAINS, THAT MAY BE DISCOVERED BÝ THE MEN OF THE U. S. ARMY IN EUROPE

France ${ }^{3}$ was a home of early man throughout a large part of the period of his evolution. In many parts of France archeological and skeletal remains of ancient man have been discovered, both before and during the war, and many doubtless lie yet in the soil. During the excavations by our men more or less ancient human remains may be repeatedly discovered; and as the scientific value of such objects is exceedingly great steps should be taken for their preservation. The medical men

3 'The same applies to Belgium and to some extent also to Italy. 
accompanying the Army could materially assist in this matter, without interference with their regular duties, by bearing the above facts in mind and calling them to the attention of the regular officers and men of the Army.

The rules to follow are simple and few in number; they are:

1. If seemingly ancient skeletal or other remains of man are encountered and circumstances permit, they should be carefully collected in their totality, even to fragments;

2. Save also whatever animal bones may be found with the human remains;

3. Note the locality and depth of the specimens from the surface, with any other facts that may seem of importance, and attach this information with the name and home address of the officer who supervised the collection, to the specimen; and

4. Pack the specimens in any convenient box and address "To The Quartermaster General, U. S. A., for the U. S. National Museum."

\section{RACIAI PROBLEMS}

The final recommendations made to the National Research Council related to the proper coöperation of the Committee with the eventual U. S. Peace Commission, in the many questions of race, etc., which are bound to come up during the final negotiations. The political fate of many of the smaller countries in Europe must be decided at these conferences. They include Belgium, Alsace-Lorraine, Poland, Lithuania, Galicia, Bohemia, the Balkans, Turkey, Arabia, Armenia and others. The Germans will undoubtedly come well prepared to claim everything to their advantage; and unless they can be confronted by anthropological facts and expert presentations of opinion they may readily gain in their unjust contentions.

As a supplement to the above recommendations the Committee also considered favorably and reported to the Council the proposition to establish a special Journal devoted to Physical Anthropology, which would pay special attention to the many anthropological problems arising in connection with or as the results of the war.

\section{CONCLUDING REMARKS}

The above statement shows in brief form the activities of the Committee on Anthropology up to the beginning of 1918. As a result of its recommendations the physical requirements for admission to the 
United States Army have been reduced. In other directions its suggestions have so far borne little fruit, but this is doubtless due in large measure to the vast amount of more urgent matters connected with the organization of a great army for the conflict abroad. The Committee has endeavored to make it clear on the one hand that Anthropology can find in the present crisis a wide field for usefulness of an immediately practical nature, and on the other, that important opportunities for scientific observation and research are afforded by the exigencies of the great conflict, the utilization of which must prove of ever increasing value as the centuries pass.

It is only just in this place to state that the various propositions herein embodied were formulated by the Secretary of the Committee. 